\title{
ERRATA
}

\section{CLINICS 2010;65(1):107-109}

RUBINSTEIN-TAYBI SYNDROME: A FEMALE PATIENT WITH A DE NOVO RECIPROCAL TRANSLOCATION T(2; 16)(Q36.3; P13.3) AND DYSGRANULOPOIESIS

\section{CASE DESCRIPTION}

Correction: The karyotype had a clerical error. The correct karyotype is $46, \mathrm{XX}, \mathrm{t}(2 ; 16)(\mathrm{p} 11.2, \mathrm{p} 13.3)$, thus, the patient presents one translocation between the short arms of chromosomes 2 and 16. 